\title{
Towards a Pedagogy for Critical Security Studies: Politics of Migration in the Classroom
}

Ali Bilgic, Loughborough University, corresponding author

Mandeep Dhami, Middlesex University

Dilek Onkal, University of Bradford

\begin{abstract}
International Relations (IR) has increasingly paid attention to critical pedagogy. Feminist, postcolonial and poststructuralist IR scholarship, in particular, have long been advancing the discussions about how to create a pluralist and democratic classroom where 'the others' of politics can be heard by the students, who can critically reflect upon complex power relations in global politics. Despite its normative position, Critical Security Studies (CSS) has so far refrained from joining this pedagogical conversation. Deriving from the literatures of postcolonial and feminist pedagogical practices, it is argued that an IR scholar in the area of CSS can contribute to the production of a critical political subject in the 'uncomfortable classroom', who reflects on violent practices of security. Three pedagogical methods will be introduced: engaging with the students' lifeworlds, revealing the positionality of security knowledge claims, and opening up the classroom to the choices about how the youth's agency can be performed beyond the classroom. The argument is illustrated through the case of forced migration with specific reference to IR and Politics students' perceptions of Syrian refugees in Turkey. The article advances the discussions in critical IR pedagogy and encourages CSS scholarship to focus on teaching in accordance with its normative position.
\end{abstract}

Keywords: critical pedagogy, critical security studies, migration, postcolonialism 
The discipline of International Relations (IR) has increasingly paid attention to critical pedagogical (CP) perspectives, mainly because critical approaches in IR have successfully raised their voices and ascertained their critical position in relation to power, both in the discipline and in the classroom. Therefore, it is not surprising that postcolonial, feminist, and poststructuralist IR scholarship have been the main addressees of critical pedagogical methods (Mohanty 1989 and 1990, Hovey 2004, Chowdhry 2007, DeLaet 2012, Parisi et al. 2013, Odysseos and Pal 2017). According to critical approaches in IR, teaching is imbued with politics; how the subject is taught and how the classroom is organised are performances where power hierarchies are challenged or reproduced. However, Critical Security Studies (CSS) has so far refrained from joining the conversation. ${ }^{1}$ This absence contradicts the said scholarship's overarching objective of problematising conventional, militarist, state-centric, and static understandings and practices of security, which are constitutive of power hierarchies globally as well as locally. This article aims to address this gap with specific reference to one of the most contentious topics in the politics of security: forced migration.

It will be argued that CP of CSS begins with building an 'uncomfortable classroom', where students are exposed to the 'positionality' of their security knowledge claims in order to reflect on their agency in the politics of security beyond the classroom. It will also be underlined that the performance of this agency depends on each student's own critical reflection on what security means and how she chooses to perform her agency. CP of CSS is not about promoting one criti-

\footnotetext{
${ }^{1}$ An exception would be a series of brief contributions in 'Interventions' section of Critical Studies on Security (2013). Some contributions will be introduced throughout the discussion, where relevant.
} 
cal approach over another, but about opening students up to analytical, ethical and political alternatives in the politics of security. Deriving from the literature on critical pedagogical practices in postcolonial and/or feminist IR (Mohanty 1989, 1990, Brydon 2004, Danielzik and Bendix 2013, Routley 2016, DeLaet 2012, Parisi et al. 2013), the present analysis asks how a scholar of CSS can contribute to the production of a political subjectivity in the classroom that would critically reflect on the politics of security where power interacts with notions and practices of security. As this is an explicitly ethical and political objective, the analysis is derived from the ongoing discussion within the discipline about how IR should be taught in order to challenge the exclusionary, violent, and oppressive relations and structures in world politics, where multiple selves and multiple others interact locally as well as globally.

Hagmann and Biersteker (2014: 294) argue that the discipline should focus on 'public pedagogical functions' in the classrooms, where IR scholars enjoy greater agency about how world politics can be taught, and which perspectives, voices and experiences are reflected upon. Amir Lupovici (2013) similarly highlights that as IR concerns relations between the self and the other in a global context with local implications, it adopts an ethical position. The IR scholar has a normative responsibility to teach students to critically engage with hegemonic, monolithic, and dichotomist identity binaries. Politics of security is one of the processes in global politics where 'the other' is produced as a threat, and where violence against it is normalised and justified. Hence, a CSS scholar faces an ethical and political responsibility in the classroom to produce subjectivities that can critically reflect on the construction of certain groups, such as refugees, as gendered and racialised 'disposable people' (Odysseos and Pal 2017: 4). We will take up this 
challenge in the case of university students in Turkey, which now hosts around 3 million Syrian refugees.

Firstly, the discussion advances the literature in critical pedagogy and IR in relation to rendering the classroom as a safe, democratic, pluralist, but concomitantly politically uncomfortable space, where students are exposed to their own situatedness in the politics of security. How security can be taught critically (i.e. teaching security and its politics in relation to complex and contingent power relations), has not been discussed in the extant literature, thus missing a critical pedagogical consideration of one of the central concepts in the discipline. Secondly, the article urges CSS teachers to take contingent power relations into account when teaching critical security in and beyond the classroom. In our case, neocolonial power relations that are produced in relation to refugees will be examined. Finally, the article introduces the scenario writing method to the pedagogy of critical security teaching. CP enables students 'to bring their own accounts of their lifeworlds into classroom discussion and develop a critique of their own social context' (Routley 2016: 488). We will make the case that it enables students to express their lifeworlds as part of a CP performance in order to expose to them how they, who are historically 'orientalised', also 'orientalise' the Arab/Middle Eastern other in the body of 'Syrian refugees'.

The practical contribution of the present research lies in the fact that migration is once again in the spotlight in Europe (and the world overall), due the asylum-seeking mass migration from Syria, particularly to Turkey. According to the United Nations, the latest number of registered Syrian refugees is $2,728,926$ (last updated 28 July 2017). In addition to the Syrians in protection centres, approximately, $80 \%-90 \%$ of Syrians are spread across Turkey outside the camps. Syrian asylum seekers are present in each of Turkey's 81 provinces. Only 12 provinces host less than 
100 Syrians, 21 of them host more than 10,000, and 7 provinces host more than 100,000. The overall number of Syrians living outside the camps is 2,000,000. From an economic point of view, the Turkish state has spent approximately 7.5 billion dollars on Syrian refugees from April 2011 to October 2015. Whereas the European Union chose to address the issue by cutting an infamous deal with Turkey in December 2015, less has been considered about in which ways the politics of security will be played out in Turkey where the post-imperial nation-state context is conducive to reproducing violent practices of security towards the Arab/Middle Eastern other.

This article is organised into four sections. Firstly, we will argue that a fundamental contribution of CSS is bringing individuals and social groups into the analysis of the politics of security in diverse ways. Whereas this normative and political contribution should be reflected in the classroom, this pedagogical practice needs to engage with important challenges stemming from the pluralism embodied within CSS. Secondly, the critical pedagogy approach will be discussed in order to argue that teaching migration through the prism of critical pedagogy is a political and ethical necessity for challenging power relations in the politics of security and dichotomist identity construction processes. Thirdly, a qualitative analysis of the scenarios written by universitylevel IR and Political Science students will be conducted with the objective of revealing their own perceptions of forced migration from Syria to Turkey. The scenarios will reveal the complex neocolonial power dynamics operating in the politics of security in Turkey. The analysis of the scenarios leads to the main focus of the article: how to teach security critically in a classroom where 'the threatened self' (Turkish state/economy/culture) and the 'threatening other' (Syrian refugees) binary is deeply entrenched in students' subjectivities. Finally, three initial steps of 
teaching forced migration/security nexus will be considered: engaging with the students' lifeworlds, revealing the positionality of security knowledge claims, and opening up the classroom to the choices about how the youth's agency can be performed beyond the classroom. These three steps aim to build up an 'uncomfortable classroom' where students question the positionality of their security knowledge claims and agency.

\section{Revisiting the Question of what CSS Stands For}

Since its inception in the early 1990s, CSS is anything but homogeneous. What security is, at which level security should be studied, whether security is 'desirable', and what constitutes (in)security have occupied the intellectual stage of CSS. Given such diversity, it would be a futile academic exercise to draw an all-inclusive picture of this pluralism. Moreover, an attempt to build a blueprint about how to teach critical security globally is also analytically and politically undesirable. That said, the diversity and pluralism of CSS is not an obstacle to remembering what CSS approaches have been collectively doing and to rethinking teaching practices based on this shared ground. This ground is that security is not considered a subject of 'high politics' beyond public discussion nor is it reserved for so-called experts, but is a political concept that is about 'us', globally and locally, or individually and collectively. In other words, CSS operates on the presumption of, and grants an agency to, individuals, groups and communities beyond the authoritative sovereign level by demystifying power relations undergirding the politics of security. How this agency is understood and what power means differ significantly. This shared ground will enable us to make a case for teaching CSS critically. 
For some approaches in CSS, the process of rendering individuals and groups agents of security is performed in two steps. The first is to conceptualise individuals and communities (below and beyond the nation) as the referents of security: objects that should be secured. Emancipatory and cosmopolitan approaches (Booth 2007; Burke 2013; Bilgic 2013), some feminist approaches (Tickner 2002; Hudson 2005), postcolonial approaches (Acharva 1997; Barkawi and Laffey 2006), and recently ethical security approaches (Nyman and Burke, 2016) argue that there are structures and relations in world politics that promote state-centric, West-centric, anthropocentric, militarist, and patriarchal security understandings which inflict violence on individuals, groups and humanity and their surrounding environments. Although security for some is pursued the expense of others, these approaches highlight the interconnectedness of security: when some individuals and groups are insecure due to their race, gender, sexual orientation, religion, nationality, and class, it is not possible to talk about security at all. Preserving their differences, these approaches articulate what true security might mean, and this normative agenda should be pursued by going beyond the confines of established structures of power. This leads to the second step: individuals and groups who are marginalised, silenced, and targeted in the name of 'security' are conceptualised as agents pursing the agenda of a different type of security (for emancipatory approaches see Basu 2013, Bilgic 2013 and 2015; for feminist approaches see Tickner 2002; Hudson 2005; Gjorv 2012). Their ideas and practices of security shape what a true security should look like. 
The majority of CSS, however, represents a more critical approach to the concept of security. The securitisation approach, for example, has long claimed that when an issue is securitised (represented as a threat), extraordinary measures are justified. The founders of securitisation theory argue that the theory itself does not promote a normative agenda about security (i.e. what security should be), but it objectively examines what security does when it is employed discursively (Waever 1995: 81, Buzan et.al 1998: 35). However, there has been on ongoing discussion about which issues should be securitised and under which conditions securitisation can be politically desirable (Hansen 2010, Floyd 2016) and undesirable (Grayson 2003; Abrahamsen 2005, Mackenzie 2009). Some explicitly argue for desecuritisation. Particularly in relation to migration, Aradau (2004) and Huysmans (2006) problematise the employment of 'the grammar of security', arguing that it creates a sense of hostility and urgency based on fear, and, therefore, reduces a complex political and social issue into a simple and uncritical binary between the self and the (migrant) other.

Securitisation theory is joined by sociological and postmodernist/poststructuralist approaches to security in interrogating the concept of security. The sociological approach, sometimes called 'the Paris School', reveals how anxiety, fear, and uneasiness are played out within the politics of security by sovereign actors. In this approach, security and insecurity are not separable; practices of security operate on the basis of and promise insecurity (Aradau 2008, Bigo and Tsoukala 2008, Neocleous 2008). Postmodernist/poststructuralist security approaches similarly underline how the threatening other has been constructed in the language of security in order to 
(re)produce the sovereign actor in domestic (Bigo, 2002) and foreign policy (Campbell, 1992). Security is a technology of governance that constantly produces control over people.

Given the aforementioned approaches' critical position towards the concept of security, they do not endorse or promote an agency for individuals and groups for the purpose of a 'better' security. However, this does not mean that they do not acknowledge this agency. In securitisation theory, the most important representative of this acknowledgement is the sociological approach to securitisation that centralises 'the audience' in the process. The concept of audience has been argued to be one of the constitutive dimensions of the securitisation practice by the pioneers of the theory. Nevertheless, it has not been theorised, but is left vague in the conventional approach (Leonard and Kaunert 2011: 59). According to Balzacq (2005: 172), this neglect originates from the underlying assumption of the 'speech act' -

that the act is universal; speech works in the same way universally by generating causal relations. In contrast, securitisation is a strategic action. This is where the audience becomes crucial. The securitising actor needs formal support (i.e. an official decision to build a wall on the borders to prevent migrant passages) and moral support from the audience, which require repeated social interaction with the audience, so the latter can be convinced that there is an existential threat to the referent object (Balzacq 2011: 9, see also, Roe 2008).

Furthermore, sociological and postmodernist/poststructuralist approaches to security also acknowledge the agency of individuals and groups not as an active audience, but because of how they understand power. Adopting the Foucault-ian understanding of power predominantly, power is not conceptualised as tangible or coercive, but as productive of subjectivities and bod- 
ies. It is diffused in social relations and produced through daily practices of individuals. Power in the politics of (in)security is practised through producing subjectivities based on fear, anxiety, and an overwhelming understanding of risk. This is a boundary-producing process between the self and other, spatially and non-spatially (Campbell, 1992; for a poststructuralist feminist approach see Shepherd 2007). Exclusionary and violent practices of security are produced, normalised and justified through the productive power of security. As some postmodernist approaches also show, this does not render individuals passive, 'docile bodies'. Resistance to (in)security can also be detected in daily practices, discourses, narratives and performances (for example, Peoples 2011). From a pedagogical perspective, Odysseos and Pal (2017) have recently conceptualised the practice of 'counter-conduct' of university students as a performance of continuous self-reflexivity and resisting 'disposability' of the other.

The differences and conflicts among the approaches in CSS cannot be omitted. That said, from different points of view, they have opened a space for studying resistance in the politics of security by involving individuals and groups as either agents of 'true' security, or as audience and producers of and resisters to power. Individuals are not considered as passive recipients of the politics of security formulated at the sovereign level. Instead, in producing or challenging it, they are considered by critical security scholars as active participants and agents of the politics of security. The question CSS scholars face is whether the pedagogy of critical security reflects and endorses this shared critical ground. Whereas all CSS approaches have an understanding of the agency of individuals and social groups, they also significantly differ. This raises the question of how to bring this diversity into the classroom. Teaching CSS critically means encouraging stu- 
dents to think about and act on their own agency in the politics of security beyond the classroom. However, this agency concerns where students position themselves in power relations historically, geographically, economically, and politically, which leads to a further issue of positionality. Approaches and theories in CSS have fundamental differences in understanding what power is and how to deal with power in relation to security. Teaching CSS critically centralises the question of power in the classroom, instead of pretending that power does not exist in a classroom where students learn about their own agency in the politics of security. Stemming from postcolonial pedagogy (Brydon 2004: 71), CP of CSS should encourage students to 'analyse how they themselves are culturally constructed as subjects-in-history', so that their knowledge claims reflect their own position in relations of power.

\section{Rethinking Critical Pedagogy for Teaching CSS}

Critical pedagogy pertains to teaching methods based on the dialectics between education and social, political, and economic relations within a given society. According to this approach, teaching is not a neutral, objective, and 'scientific' process of knowledge dissemination. Rather, by rendering the pedagogical political, education is a practice of knowledge production that not only reflects the social, but also reproduces it. Deriving originally from Antonio Gramsci, critical pedagogy accepts culture as a space through which the hegemony of certain political agents and interests is constructed (Giroux 2011, chapter 7). Education (similar to popular culture and art) is where culture is produced. However, by bringing the critical theory perspective into its understanding, critical pedagogy aims to democratise education so as to produce political actors (both 
educators and students) that use their agency to problematise and challenge hegemonic political and economic structures and relations beyond the classroom (Giroux 1997: 35-46). These actors are critical thinkers that do not accept the alleged 'neutrality' of knowledge, but instead reveal what political interests this knowledge serves. Additionally, they explore immanent potential within the social for moving towards more egalitarian, inclusionary, and pluralistic politics (Hinchey 2004: 19).

The fundamental contributions of critical pedagogy to opening up education to politics and ethics against the backdrop of violent nationalism, statism, patriarchy and neoliberal capitalism should be acknowledged. However, the approach should also be viewed cautiously in relation to teaching CSS critically. Critical pedagogy is underlined by Enlightenment philosophy, its cosmopolitan modernity (e.g. Hagmann and Biersteker 2014: 309), and dialogic rationalism (e.g. McLean 2006). This means that the approach overlooks the possibility that pedagogy, and the politics underlining it, are also susceptible to hegemonic foundationalism that objectifies 'the other'. For example, 'dialogue with the subaltern' in the framework of critical pedagogy in IR produces the subaltern, the other, as an object in the 'internationalization' of US universities' agenda (Hovey 2004). This 'exclusionary inclusion' invites 'the other' to take part in the core, as this is a performance from the position of power. In other words, CP's normative and modernist foundationalism, with Euro-centric cosmopolitan undercurrents, contradicts postmodernist/poststructuralist, some feminist, and postcolonial approaches in CSS, while appealing to emancipatory and cosmopolitan ones. Nevertheless, two important constitutive factors of critical pedagogy can still feed into the diversity of CSS and its pedagogy. 
Firstly, the important principle of critical pedagogy that appeals to CSS in general is its ethical position of human relationality. According to critical pedagogy, the cultural hegemony of instrumental rationality (i.e. 'the end justifies the means'), combined with the dominancy of ahistorical, apolitical, and technical knowledge, cancel out ethics and ethical decisions in political, economic, and social human interaction (Freire 1998: 19). This rationality represents society as an autonomous being with its own life, independent of human will and action, while promoting an individual who is self-centric, 'rational', and greedy: homo economicus par excellence (Giroux 2011: 29). In contrast, critical pedagogy aims to centralise ethics and the ethical decisions that individuals and societies face in relation to others in teaching. Knowledge produced through critical pedagogy enables the students to open themselves up to 'the other', be attentive to the experiences of others, and develop 'critical consciousness' about the contextuality and particularity of their own life experiences (Hinchey 2004: 25, Cowden and Singh 2013: 6-7, Giroux 2011: 75 and 112). This empathetic relationship serves to increase connectedness between individuals and social groups (Cowden and Singh 2013: 7).

Secondly, CP as a teaching and political practice aims at rethinking youth and its agency. This means that through the skills of critical thinking and reflection of the historicity of knowledge claims, by exploring the dialectic between knowledge and the social, youth can challenge certain political and economic structures that promote individualism, ethnocentrism, and undemocratic, exclusionary, and parochial identities. University students have a central role in this criti- 
cal political agency. As Giroux (2011: 100) argues, by hinting at the politics of security that CSS focuses on:

Higher education may be one of the few sites left in which students learn the knowledge and skills that enable them not only to mediate critically between democratic values and the demands of the corporate power and the national security state, but also to distinguish between identities founded on democratic principles and identities steeped in forms of competitive, unbridled individualism that celebrate selfinterest, profit-making, militarism, and greed.

Although CSS has brought individual agency to the core of the politics of security, it is $\mathrm{CP}$ that encourages CSS scholars to rethink the classroom in the light of this agency: CP renders CSS students agents in the politics of security through promoting the ethics of human relationality and youth agency. In addition to these two factors, CP's third important contribution in relation to CSS pedagogy is its ability to reveal and demystify power (Mohanty 1989, 1990). This not only concerns teaching CSS in a way that students understand, and problematise relations of power in the politics of security. More importantly, it is about making students reflect on their own position of power in the politics of security. CP of CSS should start with encouraging students to rethink their own historically produced and contextual power positions when they construct a social group or object as a threat to 'the self'. We will call this process 'building an uncomfortable classroom'. How they follow up this process as 'emancipators' who aim to empower the victimised groups, or an audience that challenges a securitising move, or an agent of 'counter-conduct' that continuously questions power relations, should be their choice as the CSS teacher's aim should not engender new 'epistemic authorities' (Kirby, 2013: 350).

Building an uncomfortable classroom begins with opening space for students' lifeworlds, especially in relation to what security means for them, how they consider some people as threats, and 
why. Scenario-writing can enable CSS teachers to take a step into students' lifeworlds and engage with the positionality of their security knowledge claims in a specific discursive context. In our case, this context is postcolonial power relations in Turkey, a country hosting almost three million Syrian refugees. Post-colonial context hereby refers to the post-Ottoman Empire political, economic and social relations between the elements of the Empire where Turkey (people, geography and history) represents the core and the Middle East periphery.

\section{Revealing Power in the CSS Classroom: Scenarios about Syrian Refugees in Turkey}

The student narratives of Syrian refugees are articulated within a historically constructed postimperial discursive context, where 'Arab' as people and 'the Middle East' as geography are modulated as 'the other'. Although Arabs (the Middle East and North Africa) and Turks (Anatolia and the Balkans) belonged to the same group in the millet system in the Ottoman Empire (an imperial categorisation of peoples based on their religious affiliation), the rebellion of some Arab tribes in Hejaz against the Ottoman troops during World War I not only brought the end of Ottoman rule in the Middle East, but also marked Turkey's relations with Middle Eastern countries. This mark entered the Turkish historiography of the modern nation-state, society, and culture with an infamous expression: 'the Arabs stabbed us in the back' (Jung 2005: 5).

The image of the 'untrustworthy Arab' with dubious morality gained a spatial and religious dimension when the post-imperial Turkish nation-state launched an aggressive modernisation and secularisation program. Aspiring to be a European/Western/modern nation state, the Middle East came to represent what the new nation and state was not: its significant other. The Middle 
East was often represented as a zone of conflict, where Islam introduced a type of irrationality and backwardness to the geography and its people (Karaosmanoglu 1985: 71, see also Akturk 2010). Jung (2005: 7) argues that 'as the antithesis to the rationalist project of Kemalist modernity, the Middle East was conceptualized by the stereotypes of "Western Orientalism", as a region full of superstition, inefficiency and of dubious morals'. The conflation of 'Middle East' as geography and 'Arabs' as a homogenising term to describe the Middle Eastern people pointed to the orientalised image of the region and its people in modern Turkey. Untrustworthiness, irrationality, deceptiveness, lack of hygiene, polygamy, tribal relations as opposed to national consciousness became the characteristic of the 'other', namely 'the Arab' and the Middle East, respectively.

Although relations between Turkey and Middle Eastern countries have significantly developed since the late 1990s, a relatively recent study on Arab images in the Turkish media has shown that little has changed in the othering of the Middle East/Arab. 'Murderers', 'thieves', 'traitors', 'back-stabbers', 'enemy of humanity', 'insane', 'backward', 'pirates', 'untrustworthy', 'aggressor' are some of the descriptions used in the media (Al Dakuki 2008: 290-291). Syrian refugees arrived in a post-imperial nation-state and society where orientalisation of the Middle East/Arab is still strong. However, it must be noted that in $\mathbf{2 0 1 2}$ when the first refugees arrived in Turkey, they were welcomed as a showcase of 'Turkish hospitality', 'generosity', and identified as 'brothers and sisters'. While the imperial generosity, along with political calculations, might have so far prevented the governing elite to construct the Syrian refugee movement as 'the threatening other', the public perceptions does not necessarily reflect this attitude. 
Recent academic studies conducted in Turkey regarding the public perception of Syrian refugees point to a trend towards post-imperial othering of the Middle East/Arab, which has now been reproduced in relation to the refugees. Based on her fieldwork, Nielsen argues that Syrians are now considered by the public as guests who have 'overstayed' the hospitality offered to them (Nielsen 2016). In her interviews, it was revealed that Syrians were often associated with burglary, theft, begging, disturbing once-peaceful neighbourhoods, and polygamists. One interviewee's words clearly highlighted the homogenising othering of the 'Syrians' as a category of 'other' with essentialist characteristics: 'They are like this. They have no shame and they lie all the time. It's in their culture' (Nielsen 2016: 103). Erdogan (2014: 71) similarly argues that the attitude has been shifting from positive to negative, and underlines that laziness, dirtiness, rudeness, prostitution and polygamy are frequently associated with the overall category of 'Syrians'.

There is a growing literature that examines how the (neo)colonized 'other' has become a security 'threat' to the culturally and socially 'homogenised' imperial centres (Bhambra 2016, Weber 2016: 73-91). A similar argument can be made for non-Western postcolonial states. The context where we conducted the present research (i.e., university) underlines two fundamental factors why teaching critical security through critical pedagogical methods is politically necessary. Primarily, with the arrival of Syrian refugees in significantly high numbers, the cultural, political, and geographical 'other' of the modern Turkish 'self' have now settled and become residents within the territorial borders. Orientalized imaginations of the Middle East/Arab other are now 
revived in the body and identity of the 'Syrian refugee', who invokes fear, unease and anxiety in the 'self' because s/he is no longer 'out there', but 'here', by challenging the historically established self and its subjectivity. Secondly, the construction of the Syrians as a threat to the self is performed through reproducing postcolonial power hierarchy between the Turks/Turkey and Arabs/Middle East. Given these two factors, teaching critical security requires a serious engagement with postcolonial power relations by encouraging university students to reflect on how they are 'culturally produced subjects-in-history' (Brydon 2004: 71). The research based on a scenario writing method, which will be discussed next, enabled us to understand the extent to which students were aware of the 'positionality' of security knowledge claims in relation to the 'Syrians' construed as 'threats'.

In the guidelines given to the students that participated in the present research at the end of 2016, we stated that 'We want you to imagine that the Turkish government decides to ban all Syrian refugees from entering Turkey, effective immediately. Using the scenario generation technique you have been taught, we would like you to think about the scenarios (as many as you can) that might occur as a consequence of this policy decision within the next 6 months.' The scenario-writing method enabled a number of advantages for this research, which is fundamentally interested in what types of security narratives students construct in relation to the Syrian refugees residing in Turkey. One advantage of scenarios is that they enabled us to detect the cognitive and affective links that the students themselves established when they created them. As they were writing their own stories, they narrated about themselves, their 'lifeworlds' as put by $\mathrm{CP}$, how they perceived the country they lived in, and how they perceived the Syrian 
refugees residing in the country. Their fears and aspirations about the present and future were crystallised in their stories about 'Turkey-after-the-ban'. As most of them imagined a more 'secure' Turkey after the ban, this point will be crucial in our last section about teaching forced migration in relation to CSS.

A primary finding of the analysis was that only 4 students out of 40 wrote their scenarios from the perspective of the Syrian refugees (from the perspective of 'the other'). They highlighted that the banned refugees would be stuck between the fighting forces in Syria, face grave insecurities, and be forced to rely on smuggling networks to facilitate their flight. In particular, one participant (C17) adopted a very different approach from the rest, and put himself in the shoes of a Syrian male refugee. By using the first-person story-telling method, he imagined a Syrian refugee who is a father of four, who had a job in Syria, but with the war had to migrate to Turkey where he had relatives. Following the ban, he finds himself in fear of being repatriated to Syria and goes 'illegal' in order not to be apprehended. Another refugee-centred point of view was from participant $\mathrm{C5}$, who argued that with the ban, the government can place a greater focus on the existing refugees and distribute financial aid more effectively.

Thirty-six students' scenarios revolved around the positive economic, political, and social consequences of the ban for Turkey. The themes about the Syrian refugees were the causal links that the students cognitively and affectively produced in their scenarios about the refugee presence 
in the country and perceived economic, political, and social problems stemming from this particular presence.

The majority of students imagined that the ban would be beneficial for the Turkish economy. Twenty-three (out of 36) clearly stated that the ban would remove the cost of Syrian refugees from the Turkish state/economy. Two themes emerged to explain how this cost would be decreased. The first was 'fewer refugees means more jobs for Turkish people'. Several students wrote that since the refugees were paid less and sometimes worked illegally, the employers preferred them over the 'natives', a situation which, in their narratives, caused unemployment among Turkish people. The 'cheap labour' representation of the refugees, in one participant's scenario (C44), appeared in a different way: the ban would affect the economy negatively because Turkey would lose cheap labour.

The second theme was that the ban would increase the welfare benefits of the Turkish citizens, since the welfare system is currently overwhelmed by the Syrian refugees. One participant (C04) imagined that the ban would lead to lower taxes for the citizens, implying that taxes are rising because of the costs of having Syrian refugees in Turkey. These articulations are strikingly similar to the economic discourse against migration in developed countries. Reproduction of refugees as an economic burden and cheap labour is constitutive to the power hierarchy between the developed citizen and underdeveloped non-citizen, who is 'out of her place' (Weber 2016). The narrative strips Syrian refugees of their need for international protection and orientalizes 
them as a homogenous group that threatens the economic security of 'the self': 'they' are not in Turkey for protection but steal from 'us'.

By producing Syrian refugees as a threat to 'the self', in the students' scenarios a ban on refugees would bring 'more domestic security to Turkey'. This is a zero-sum security notion where the other's security means less security for the self. The reasoning that some students formulated was that the process of Syrians becoming 'another' minority in Turkey (like 'Kurds' or 'Alevites') would be halted with the ban, and 5 students clearly stated that the ban would prevent a possible 'civil war' between Turks, Kurds, and Syrians. Meanwhile, most scenarios used the words 'chaos' to describe the current situation. According to two participants (i.e., C39 and C1), the ban would increase Turkish state's 'sovereignty' on its territory. However, some students wrote that the ban would also pre-empt the possibility of Syrians asking for 'rights'. One participant (C38) imagined that 'among more than 2 million Syrian refugees, a new ethnic problem might emerge similar to Alevis and Kurdish citizens. Turkey's unity will be under threat'. Another participant (C37) wrote:

All the refugees will rush to gain citizenship, fake marriages, or maybe even getting pregnant will be the most used methods. Kurdish people may support these people since they know what it is like to be a 'minority'. They may come together and become a strong civil terror. There may fight for rights, land etc. even more than before. 
The fear that the Syrian refugees 'can rebel' is also articulated in a different way. The ban would not solve 'the problem' of Syrians, since they were already in Turkey. Five students were explicitly concerned about this possibility.

In relation to protecting the societal/cultural identity of 'the Turkish self', the ban was often modulated as a way to protect or facilitate 'cultural harmony' within society. This is the sphere where the orientalised Arab image was powerfully reproduced. None of the students considered common religion as a shared identity. Reflecting the official historiography in Turkey, only one participant (C20) mentioned religion, although he continued that this would not be enough to build a common identity with Syrian refugees. A repeated issue in the scenarios was national education in Turkey, which was at risk due to the 'Arab' effect. Some students wrote that universities should not accept Syrian refugees. Thirteen students explicitly argued that the ban would contribute to decreasing crime rates in Turkey; five stated that drug trafficking would decrease; and six said that violence in general would decrease. One participant (C29) stated that the Syrian refugees were a source of 'illness' and 'pollution'. Two students wrote that the 'rape problem' could also be dealt with by the ban. Participant C6 wrote the following in reflection on the current situation:

Cultural differences between Syrian refugees [and Turkish citizens] is another important social problem. Unfortunately, within one year, the incidence of rape, which is one of the most important social problems, increased. I imagine that when the Turkish government bans these refugees from coming to Turkey, the frequency of these social problems can be decreased. 
Three conclusions can be drawn from the scenarios that the students produced. Firstly, students constructed Syrian refugees as a threatening homogenous 'other' to Turkey's economic, political and social security, as the ban was regarded as a way to address these threats; their disposability was thus consented to. No threat perception was observed regarding Turkey's foreign policy, although the ban was often articulated as a 'potential' foreign policy problem, especially with the EU. Secondly, the scapegoating of Syrian refugees as responsible for Turkey's social, economic, and political problems is overwhelmingly evident in the students' perceptions. The ban was understood as a shortcut to solving these problems. As a typical corollary of scapegoating, the Syrian refugees were considered as a homogeneous social bloc that is a burden to the welfare, education, healthcare, and economy, as well as a threat to internal peace and a source of crime and violence. Furthermore, 'they' were perceived as a challenge to an imagined homogenous 'we'. The students associated them with the deeply entrenched insecurity of civil war, rights-seeking minorities, and land-demanding ethnic groups in Turkey. Finally, religion played almost no role in the students' scenarios, neither as a dividing nor unifying factor.

The challenge for a CSS teacher hereby is how to address the identity dichotomies between the self as ' $I$ '/'we' and the threatening other as 'they' in the classroom, so that IR and Political Science students can become aware of their own power positions in the politics of security as agents. This agency can be practiced either as producing power relations or as challenging them. Therefore, a CSS teacher faces two challenging tasks: firstly, revealing the positionality of students in their security knowledge claims; and secondly, opening the classroom to ways of challenging power either as 'emancipators', 'audience', or agents of 'counter-conduct'. 


\section{Building an Uncomfortable CSS Classroom in a Postcolonial Context}

How can CSS, which has brought critical individual agency to the analysis of security, be taught in a classroom, such as the one discussed previously, where students make articulations about the 'threatening other' deriving from the historical-cultural context? Can teaching CSS contribute to the production of self-reflective students who resist violent and exclusionary practices of security and their 'disposable others'? How can educators of CSS encourage students to rethink their own agency in the politics of security? How can they become 'other-regarding'? The following discussion will offer three initial steps to the CSS teachers to build an 'uncomfortable classroom', while taking the fundamental differences among the CSS approaches about security and agency into account: engaging with the students' lifeworlds, revealing the positionality of security knowledge claims, and opening up the classroom to choices on how the youth's agency can be performed beyond the classroom.

Burgess (2011: 133) argues:

security and insecurity are implicitly connected to what we value, an expression of a value constellation that expresses a certain perspective on life, of individual and collective anxieties and aspirations, of expectations about what to sacrifice and what is worth preserving ... It involves people who value things and who need certain things as a means to survive.

Students (and teachers) in the classroom are not exceptions. Security and insecurity are not simply objects to be studied, implying a hypothetical and allegedly scientific distance between the subject and object. Instead, security and insecurity are part of the students' daily lives. In the above scenarios, students told stories about their own insecurities, for example, about how the ban would stop the 'Arabic' influence on Turkish culture, halt the admission of Syrians into universities, increase jobs, and decrease illness or rape. These insecurities cannot be privatized. Ra- 
ther, they are products of the post-colonial discursive context in Turkey about migrants, foreigners, or Arabs. The identity binaries of the politics of security, that is, the threatened self and the threatening other, are power-driven. This means that different power hierarchies (race, sex, class, gender, nationality, and so on) intertwine with what security means (Whose security should be pursued? How can security be pursued?). This is one of the fundamental contributions of CSS. A way to reflect and operationalise this contribution is to make power and privilege visible in the classroom. Taking advantage of the pluralism of insecurities shared in the classroom, the teacher encourages students to reflect upon how their construction of the 'threatening other' is performed from a position of power that colonial hierarchies have placed them in at this point in history. This can be done through building an 'uncomfortable classroom'.

Uncomfortable classroom (in relation to CSS teaching) refers to a pluralist and democratic space where teaching CSS is, first and foremost, performed through exposing students to their own power positions in making security knowledge claims. This power position is often enacted through creating knowledge about who/what is a threat to whom and how the threat can be addressed by (re)drawing dichotomist identity boundaries. Uncomfortable classroom aims to reveal this power relationship by dismantling the comfort of established security knowledge claims.

Building an 'uncomfortable classroom' can be performed in three steps. The first one concerns engaging with students' lifeworlds rather than rendering them as passive audience. In our exercise, we did this through the scenario-writing method, which allowed us to comprehend the students' security-knowledge claims in their own words: how do they make claims about who is 
threatening, how is the threat constructed, and what types of practices they see suitable to address the threat? The second step is revealing the positionality of their knowledge and challenging it. In our case, it was revealing how postcolonial power relations shaped their ideas about Syrian refugees and why and how the latter was defined as 'threatening'. The final step is related to the question of youth agency. After students are exposed to their agency in constructing 'the threatening other' in the previous one, the third step will introduce them to alternative agencies as conceptualised by CSS. Now we will explore these steps in detail.

The first step is to perform 'engaged pedagogy'. 'Engaged pedagogy' (hooks, 1994: 13-22) refers to a process of creating a classroom where the teacher engages with students' own stories and their life narratives. An objective of such engagement is to transform the classroom into a pluralist space where students from different racial, gender, sexual orientation, and class backgrounds can share their own experiences with the teacher and peers. Another objective is to prompt students to rethink their own subject positions in political, economic, and social relations. This is an essential dimension of critical pedagogy, which postcolonial and/or feminist pedagogy also strongly shares and is highly relevant to the present case (Mohanty 1989 and 1990, Routley 2016, DeLaet 2012). The overwhelming majority of students we engaged with were Turkish of uppermiddle and upper class backgrounds. Their scenarios enabled us to understand how their subjectivities were played out in their narratives about 'after-the-ban', reproducing postcolonial power hierarchies in the body of the Syrian refugee. Their lifeworlds, expressed in the scenarios, powerfully reveal what types of power relations exist in the classroom, which a CSS teacher should address prior to the teaching. Hence, based on this engagement, we have formulated the following practices that a CSS teacher can conduct in teaching security critically. 
In the case of teaching the development-security nexus in the Global North, Denielzik and Bendix (2013: 353) argue that when the history of neocolonial relations is brought into the classroom, it may lead students to question 'the global position of power that used to be questioned or regarded as deserved'. Similar colonial power relations can also be observed within the Global South, as discussed above. Therefore, the second step starts with the CSS teacher questioning the historical and political context in which the Syrian refugees are constructed as a threat. A threat of violence from ethnically different groups, right-demanding minorities, economic hardships, and violence towards women is a deeply entrenched insecurity in Turkey. The point here is to produce a self-reflexive subjectivity that questions the discursive context, where certain colonised groups are repeatedly constructed as a threat to the 'homogenous self'.

There are multiple methods that can be employed in this step. A possible method is to show the world through the eye of the refugee, the threatening other: what the other sees in the self, host country, and community, so the self can acknowledge its power position. For example, do the Syrian refugees really overwhelm health services; what types of problems they face in their daily lives in the host society; and what do they think of us? It must be noted that the teacher is responsible for reflecting pluralism in 'the other', so the homogenous 'they' can be challenged. Engaging with the other's narrative is an exercise whereby students are exposed to how their own stories clash or conflate with the others'. Therefore, a student's subjectivity is produced that involves multiple selves and others (Lupovici 2013). In our case, the four student participants, especially the one written as a story of a Syrian refugee, can be used to demonstrate that it is possible to attempt becoming 'the other', and conflating the student's lifeworld with the refugee's: an interruption of the orientalised other's dehumanization in the classroom (el-Malik, 
2013). Surely, the latter is simply a perception of the student, and does not necessarily reflect an accurate account. However, in the CSS classroom, it can be an example of the possibility of blurring the border between the self and the other and looking at the self through the eyes of the other.

Two primary rewards of this practice are deconstructing the myth about homogeneity of 'the other' and 'the self' (DeLeat, 2012: 257), and revealing 'complementarity and interdependency' between the self and the other (Chowdry, 2007: 104), in parallel with CP's focus on human relationality. It must be noted that these encounters can be uncomfortable for the students, not only because they challenge the certainty that an individual seeks by constructing an identity for herself, but also, and potentially more importantly, because they reveal their own power positions in neocolonial and other hierarchies (Parisi et.al. 2013: 418; Danielzik and Bendix, 2013: 353). Another important caveat is that examples and stories of 'the other' can also be used to reproduce the power position of the self (Routley 2016: 491, see; also Mohanty 1989-1990: 194). For example, one of the four participants (C2) problematised the ban because it contradicted the hospitality culture of the Turkish nation. The aim must be to demystify colonial power, not reproduce it.

Another method is called 'provincializing Turkey' in order to expose students to their subordinated position in global neocolonial power hierarchies. This method is similar to Routley's (2016: 490) 'decentring Europe' in teaching Africa in the British context, where the students are 
exposed to how African migrants exoticize Europe. Provincializing Turkey means bringing the question of how migrants from Turkey are subjected to a similar neocolonial narrative in European states by orientalising them (i.e. threat to culture, source of crime, burden on the welfare system, and so on). By converting the threatened self in one context into the threatening other in another, this method can be useful for demystifying the borders between 'the self' and 'the other', but also discomforting for the students. This is mainly because their object position in the politics of security is denied in a different context and produced as subjects of subordination in neocolonial power hierarchies.

Following the potentially uncomfortable encounters with the others, the final step is to raise questions in the classroom regarding the agency of the students, or youth's critical agency as put by $\mathrm{CP}$, in the politics of security beyond the classroom. Therefore, the question is how the students imagine their agency when they leave the classroom. Mohanty (1989, 1990: 206-207, italics original) argues that critical postcolonial/feminist pedagogy is part of a larger struggle called 'public culture of dissent', which 'entails creating spaces for epistemological standpoints that are grounded in the interests of people and which recognize the materiality of conflict, of privilege and of domination'. The politics of security is one of the core areas where this materiality can be observed but also challenged through epistemological standpoints within CSS. The CSS teacher is responsible for creating a classroom where students can imagine their agency as either empowering refugees, or challenging the securitisation of forced migration, or as a Foucaltian 'counter conduct'. As Kirby (2013: 349) rightly argues, 'the critical schoolmaster can fall just as easily into explication, seeking to bring students, by degrees, to her own level of criticality' risking new 'epistemic authorities'. Fighting such temptation, regardless of which resistance the CSS teacher 
leans towards, the classroom should be organised to allow students to imagine all these alternatives as practices of their critical agency. The warning of Brydon (2004: 64) on postcolonial pedagogy can be repeated for CP of CSS: it 'should not be in the business of producing converts to a cause, however worthy, because all causes can be perverted'.

A caveat is in order. Uncomfortable classroom is uncomfortable also for the CSS teacher. Primarily she leaves the comfort of teaching CSS through conventional ways and takes a risky journey towards developing an engaged relationship with the students in order to make them uncomfortable as some students may express discontent when their privilege is exposed or their countries are 'provincialised'. One reward, however, is to teach CSS by being true to its politics and ethics. Moreover, the CSS teacher can also experience her own positionality. It is important to note that during the scenario-writing and their assessments, we conducted our analyses from our own privileged point. CSS teachers can address their own positionality by abandoning the hierarchical relation with the students. Scenarios can hereby be helpful again. Since students become active participants of teaching through scenarios, who voice their opinions freely and democratically, the hierarchical relation between the teacher and the student crumbles. Therefore, the more the CSS teacher engages with the students, the more she is exposed to her power position.

\section{Conclusion}


Teaching is political, as the pioneer of critical pedagogy, Paulo Freire (1970), argues in Pedagogy of the Oppressed. This is because education is not simply an area where hegemonic ideologies are produced on the cultural plane; it is also where these hegemonies are decentred and challenged through critical educational practices. Following Freire and other approaches in critical IR that recognise the political role of the classroom, this article has argued for a case on how CSS can be taught critically. Rather than being a 'neutral' transferor of conceptual discussions within CSS or training students for them to reach her critical level, the CSS teacher/educator faces an ethical and political responsibility in the classroom: rendering students agents in the politics of security by exposing them the positionality of their security knowledge claims. Three initial steps have been offered. These are engaging with the students' lifeworlds, revealing the positionality of security knowledge claims, and opening up the classroom to choices on how the youth's agency can be performed beyond the classroom. We have conceptualised these steps based on our own interaction with university students in Turkey, who were asked to write their own scenarios about what might occur during a six month period after a ban on Syrian refugees.

CSS, whether narrowly conceived as 'the three schools' or broadly by involving feminist, postmodernist, postcolonial strands, destabilises the established conceptions and practices of security by revealing the power relations operating through them. However conceptualised, security as a political tool, technology of governance, and normative objective of the sovereign body (re)draws boundaries, (re)produces subjectivities, and (re)construct identities. This renders teaching critical security a 'political' act: it demystifies and exposes power in the politics of security. The CSS classroom is not an apolitical and ahistorical space of education, but a space where students are encouraged to rethink their own agency in the politics of security. 
Fear, anxiety and unease are often studied by scholars of critical security (among others, Bigo 2002, Huysmans 2006), whereas less has been revealed about how these emotions targeting 'the threat' are historically produced through colonial power relations. There is now a growing literature that demystifies the neocolonial power relations vis-a-vis migration from the Global South to the Global North. This article moves the discussion to a non-Western postcolonial nation-state context. The move has been pedagogically practiced to reveal how a non-Western student subject, who is 'orientalised', also 'orientalises' its historical postcolonial 'other' as a security threat when the other moves into the 'secured' borders of 'the self'.

The final contribution of the article concerns the importance of scenario-writing as a way of engaging with students' lifeworlds. Although the scenario-writing method is not common in IR, its importance lies in encouraging students to imagine creatively within predefined conditions. Students write individually and freely without concerns of judgment from peers or the educator, unlike face-to-face interviews, and in their own words, unlike questionnaires and surveys. From a critical pedagogical perspective, scenario-writing facilitates honest and free engagement with the students and among students and, in our case, constituted the first step towards building an uncomfortable classroom. For CSS scholars, it enables them to observe not simply what kind of power relations exist, but, more importantly, how these power relations are constructed in student's own narratives with the objective of exposing them to their own 'positionality'.

\section{Notes}

The research was partly supported by HM Government funding to MK Dhami.

\section{References}


Abrahamsen, Rita. 2005. "Blair's Africa: the politics of securitization and fear." Alternatives 30: $55-80$.

Acharya, Amitav. 1997. “The Periphery as the Core: The Third World and Security Studies.” In Critical Security Studies: Concepts and Cases, edited by Keith Krause and Michael C. Williams, 299-328, University of Minnesota Press, 1997,

Akturk, Ahmet Sener. 2010. “Arabs in Kemalist Turkish Historiography." Middle Eastern Studies, 46(5): 633-653.

Al Dakuki, Ibrahim. 2008. "Arab and Turkish Images of Each Other.” In Imagining the Arab Other: How Arabs and Non-Arabs View Each Other, edited by Tahar Labib, 284-315, London, I.B. Tauris.

Aradau, Claudia. 2004. "Security and the democratic scene: Desecuritization and emancipation." Journal of International Relations and Development 7: 388-413.

Aradau, Claudia. 2008. Rethinking trafficking in women. Politics out of Security. London: Palgrave Macmillan.

Balzacq, Thierry. 2005. "The three faces of securitization: Political agency, audience and context.” European Journal of International Relations 11:171-201.

2011. "A theory of securitization: origins, core assumptions, and variants." In Securitization Theory: How Security Problems Emerge and Dissolve, edited by Thierry Balzacq, 1-30, London: Routledge.

Barkawi, Tarak, and Mark Laffey. 2006. "The postcolonial moment in security studies." Review of International Studies, 32: 329-352. 
Basu, Soumita. 2013. "Emancipatory Potential in Feminist Security Studies.” International Studies Perspectives, 14: 455-458.

Bhambra, Gurminder K. 2016. "Whither Europe? Postcolonial versus neocolonial cosmopolitanism." Interventions, 18: 187-202.

Bilgic, Ali. 2013. Rethinking Security in the Age of Migration: Trust and Emancipation in Europe. London: Routledge.

2015. “'Real people in real places': Conceptualizing power for emancipatory security through Tahrir.” Security Dialogue, 46: 272-290.

Bigo, Didier. 2002. "Security and immigration: toward a critique of the governmentality of unease." Alternatives 27: 63-92.

and Anastassia Tsoukala, eds. 2008. Terror, insecurity and liberty: illiberal practices of liberal regimes after 9/11. London: Routledge.

Booth, K. 2007. Theory of world security. Cambridge: Cambridge University Press.

Boswell, Christina. 2007. "Migration Control in Europe after 9/11: Explaining the Absence of Securitisation” Journal of Common Market Studies 45: 589-610.

Buonfino, Alessandra. 2004. "Between Unity and Plurality: the Politicization and Securitisation of the Discourse of Immigration in Europe" New Political Science 26: 23-49.

Burgess, Peter. 2011. The Ethical Subject of Security: Geopolitical Reason and the Threat Against Europe. London: Routledge.

Burke, Anthony. 2013. "Security cosmopolitanism.” Critical Studies on Security, 1(1): 13-28. 
Buzan, Barry, Ole Wæver, and Jaap De Wilde (1998) Security: a new framework for analysis. London: Lynne Rienner Publisher.

Byrdon, Diana (2004). “Cross-talk, Postcolonial Pedagogy, and Transnational Literacy." In Home-work : postcolonialism, pedagogy and Canadian literature, edited by Cynthia Sugars, 5771, Ottowa: University of Ottowa Press.

Campbell, David. 1992. Writing security: United States foreign policy and the politics of identity. U of Minnesota Press.

Chowdhry, Geeta. 2007. "Edward Said and contrapuntal reading: Implications for critical interventions in international relations." Millennium, 36: 101-116.

Collective, C. A. S. E. 2006. "Critical approaches to security in Europe: A networked manifesto." Security Dialogue 37: 443-487.

Cowden, Stephen, and Gurnam Singh. 2013. Acts of Knowing: Critical Pedagogy in, against and beyond the University. New York: Bloomsbury Publishing.

Danielzik, Chandra-Milena and Daniel Bendix. 2013. “(In)security in postcolonial development education in Germany." Critical Studies on Security, 1: 352-354.

DeLaet, Debra. 2012. "Interrogating "they": A pedagogy of feminist pluralism in the international relations classroom.” International Studies Perspectives 13: 254-269.

El-Malik, Shiera S. 2013. “Critical Pedagogy as Interrupting Thingification.” Critical Studies on Security, 1: 361-364.

Erdogan, Murat. 2014. "Perceptions of Syrians in Turkey.” Insight Turkey, 16: 65-76. 
Floyd, Rita. 2016. "The Promise of Theories of Just Securitisation.” In Ethical Security Studies: A New Research Agenda, edited by Joanna Nyman and Anthony Burke, 75-88, London: Routledge.

Freire, Paulo. 1970. Pedagogy of the Oppressed, translated by Myra Bergman Ramos. New York: Continuum (1970).

-1998. Pedagogy of freedom: Ethics, democracy, and civic courage. London: Rowman \& Littlefield.

Giroux, Henry A. 1997. Pedagogy and the Politics of Hope Theory, Culture, and Schooling: A Critical Reader. New York: Perseus.

2011. On Critical Pedagogy. New York: Bloomsbury Publishing.

Grayson, Kyle. 2003. "Securitization and the boomerang debate: A rejoinder to Liotta and SmithWindsor.” Security Dialogue, 34: 337-343.

Gjørv, Gunhild Hoogensen. 2012. "Security by any other name: negative security, positive security, and a multi-actor security approach." Review of international Studies 38: 835-859.

Hagmann, Jonas, \& Thomas J. Biersteker. 2014. "Beyond the published discipline: Toward a critical pedagogy of international studies.” European Journal of International Relations 20: 291-315.

Hansen, Lene. 2000. "The little mermaid's silent security dilemma and the absence of gender in the Copenhagen School.” Millennium 29: 285-306.

Hinchey, Patricia H. 2004. Becoming a critical educator: defining a classroom indentity, designing a critical pedagogy. New York: Peter Lang. 
hooks, bell. 1994. Teaching to Transgress: education as the practice of freedom, London: Routledge.

Hovey, Rebecca. 2004. "Critical pedagogy and international studies: Reconstructing knowledge through dialogue with the subaltern.” International Relations 18: 241-254.

Hudson, Heidi. 2005. “'Doing' security as though humans matter: A feminist perspective on gender and the politics of human security." Security Dialogue, 36: 155-174.

Huysmans, Jef. 2006. The Politics of Insecurity: Fear, Migration and Asylum in the EU. London: Routledge.

Jung, Deitrich. 2005. "Turkey and the Arab world: historical narratives and new political realities." Mediterranean Politics, 10(1):1-17.

Karaosmanoglu, Ali. 1985. "Islam and foreign policy: a Turkish perspective." Foreign Policy, 12(1-2): 64-78

Kirby, Paul. 2013. “The Unapologetic Schoolmaster.” Critical Studies on Security, 1: 349-351.

Leonard, Sarah, and Christian Kaunert. 2011. "Reconceptualizing the audience." In Securitization Theory: How Security Problems Emerge and Dissolve, edited by Thierry Balzacq, 57-76, London: Routledge.

Lupovici, Amir. 2013. "Me and the Other in International Relations: An Alternative Pluralist International Relations 101.” International Studies Perspectives, 14: 235-254.

MacKenzie, Megan. 2009. "Securitization and desecuritization: Female soldiers and the reconstruction of women in post-conflict Sierra Leone." Security Studies 18: 241-261. 
McLean, Monica. 2006. Pedagogy and the university: Critical theory and practice. New York: Bloomsbury Publishing.

Mohanty, T. Cahandry. 1989-1990. “On race and voice: Challenges for liberal education in the 1990s." Cultural Critique 14:179-208.

Neocleous, Mark. 2008. Critique of security. Edinburgh: Edinburgh University Press.

Nielsen, Selin Yildiz. 2016. "Perceptions between Syrian Refugees and Their Host Community." Turkish Policy Quarterly, 15: 99-106.

Nyman, Jonna, and Anthony Burke, eds. 2016. Ethical Security Studies: A New Research Agenda. London: Routledge.

Odysseos, Louiza and Pal, Maia. 2017. "Towards Critical Pedagogies of the International? Student Resistance, Other-regardedness and Self-formation in the Neoliberal University." International Studies Perspectives forthcoming.

Parisi, Laura, Julianne E. Allison, Janni Aragon, Debra DeLaet, Elina Penttinen, Helle Rytkønen, Ellie Schemenauer, Simona Sharoni, and Heather A. Smith. 2013. "Innovating International Relations Pedagogy: Critical Feminist Engagements." International Feminist Journal of Politics, 15: 412-425.

Roe, Paul. 2008. "The 'value'of positive security." Review of International Studies 34: 777-794.

Routley, Laura. 2016. "Teaching Africa, presenting, representing and the importance of who is in the classroom." Politics, 36: 482-494. 
Shepherd, Laura J. 2007. “"Victims, Perpetrators and Actors' Revisited: Exploring the Potential for a Feminist Reconceptualisation of (International) Security and (Gender) Violence." The British Journal of Politics and International Relations 9: 239-256.

Peoples, Columba. 2011. "Security after emancipation? Critical theory, violence and resistance." Review of International Studies, 37: 1113-1135.

Tickner, J. Ann. 2002. "Feminist perspectives on 9/11.” International Studies Perspectives, 3: 333-350.

Waever, Ole. 1993. "The Societal Security." In Identity, Migration and New Security Agenda in Europe, edited by Barry Buzan, Morten Kelstrup, Pierre Lemaitre, and Ole Waever, 17-40, London: Pinter Publishers.

Weber, Cynthia. 2016. Queer International Relations. Oxford: Oxford University Press. 